\title{
O CURSO DE PLANEJAMENTO DA FACULDADE DE SAÚdE PÚBLICA DA UNIVERSIDADE DE SÃO PAULO \\ Ensaio de avaliação
}

Reinaldo RAMOS * Aracy WITT *

\begin{abstract}
RAMos, R. \& WITT, A. - o curso de planejamento da Faculdade de Saúde Pública da Universidade de São Paulo: ensaio de avaliação. Rev. Saúde públ., S. Paulo, 8:155-62, 1974.

RESUMO: Após descreverem sucintamente a organização $e$ conteúdo do curso de especialização em planejamento do setor saúde, da Faculdade de Saúde Pública da USP, foram relatados os resultados de uma pesquisa levada a efeito junto a profissionais preparados no referido curso, no periodo de 1968 $a$ 1972. A despeito de algumas falhas apontadas, os entrevistados, em sua maioria, manifestaram a opinião de que os conhecimentos e técnicas ministrados asseguram capacitação suficiente para o desempenho da função planejadora. As maiores dificuldades por eles sentidas dizem respeito a deficiencias da máquina administrativa dos serviços de saúde, à escassez de pessoal $e$ de verbas e à falta de apoio central, regional e local. Algumas medidas são sugeridas, objetivando a eliminação ou atenuação dessas dificuldades.
\end{abstract}

UNITERmos: Planejamento de Saúde (curso)*; Fraculdade de Saude Píblica da USP*; Avaliação*; Treinamento (planejadores); Recursos Humanos.

\section{I N T RODUCAO}

Desde 1968 vem a Faculdade de Saúde Pública da Universidade de São Paulo, com recursos próprios e contando ainda com a colaboração de outras instituiçōes, realizando regularmente cursos para a formação de especialistas em planejamento do setor saúde.

Tais cursos - com duração de 16 semanas, correspondendo a uma carga total de aproximadamente 480 horas de trabalhos escolares - têm sido promovi- dos visando aos seguintes objetivos gerais :

a) ministrar ensino intensivo sobre os princípios e métodos do planejamen. to de saúde;

b) familiarizar os participantes com os conceitos, métodos e conteúdo da programação econômica e social;

c) propiciar o intercâmbio de conhecimentos e experiências.

- Do Departamento de Prática de Saúde Pública da Faculdade de Saúde Pública da USP Av. Dr. Arnaldo, 715 - São Paulo, SP - Brasil 
RAMOS, R. \& WITT, A. - o curso de planejamento da Faculdade de Saúde Pública da Universidade de São Paulo: ensalo de avaliação. Rev. Saúde públ., S. Paulo, 8:155-62, 1974.

Especificamente, destinam-se ao preparo de profissionais para o exercício de funções de planejamento do setor saúde, ou que, desenvolvendo atividades docentes em institutos universitários, possam de alguma forma contribuir para a divulga. ção e implantaçáo do processo.

Considerando os objetivos dos cursos de planejamento do setor saúde, acima especificados, conclui-se que eles não têm ou não devem ter finalidade meramente acadêmica ou especulativa, o que torna evidente a necessidade de que a seleção dos candidatos obedeça a um recrutamento de tipo preferencial, Daí porque, entre nós, os candidatos devem possuir formação básica em saúde pública e experiência mínima de dois anos em função técnica, administrativa ou docente no campo da saúde, exigindo-se-lhes, ademais, vínculo empregatício a uma organização de saúde. Este último requisito é considerado de suma importância, porque de certo modo compromete a instituição ao adequado aproveitamento do candidato, após a conclusão do curso.

Por outro lado - e este aspecto já foi salientado em trabalho anterior sobre o assunto ${ }^{1}$ - em razão de ser o Brasil um país federativo, não se pode pensar em planejamento apenas em termos nacionais, a cargo das instituições do setor saúde atuando na esfera federal. Há que ter em vista também o planejamento nas esferas estadual e territorial, abrangendo o espaço geográfico de cada um dos vinte e dois estados e três territórios federais em que está dividido o país. E mais ainda: face à existência de problemas comuns a vários estados - problemas esses por vezes de caráter agudo, a reclamarem tratamento prioritário - o governo federal vem adotando a política de criação de organismos macro-regionais (SUDAM, SUDENE, SUDECO, SUVALE, SUDESUL), destinados a promover o desenvol. vimento sócio-econômico dessas áreas, aí incluidos, obviamente, os aspectos relacionados ao setor saúde.
Ante essa multiplicidade de esferas federal, estadual e macro-regional - e sem mencionar o nivel local, é compreensivel que os cursos brasileirps de planejamento do setor não possam restringir-se apenas ao preparo de pessoal para a formulação de planos nacionais de saúde, mas, genericamente, para o exercício de funções de planejamento de saúde em quaisquer esferas e níveis.

Feitas estas considerações gerais sobre os cursos de planejamento de saúde ministrados pela Faculdade de Saúde Pública da USP, restaria uma referência ao seu conteúdo, 0 curso compreende cinco partes distintas e de duração variável, a saber:

1) as primeiras cinco semanas são dedicadas a um programa introdutório, compreendendo a apresentação e discussão de temas de administração geral e pública, O. \& M., economia, estatística, sociologia da administração e noções de contabilidade. Essa unidade tem por objetivos atualizar conhecimentos, uniformizar conceitos e suprir eventuais deficiências na formação básica dos candidatos;

2) a segunda parte do curso, estendendo-se por uma semana, compreende a apresentação dos seguintes temas: conceituação de desenvolvimento $\mathrm{e}$ subdesenvolvimento econômico; conceituação de modelo e apresentação de modelos de desenvolvimento global; discussão dos esquemas conceitual e operacional do planejamento de saúde; conceituação e apresentação panorâmica das técnicas de planejamento de saúde;

3) as oito semanas seguintes destinamse ao estudo pormenorizado dos vários instrumentos metodológicos de planejamento de saúde - técnicas de programação local, de programação do setor público, de elaboração e avaliação de projetos de investimentos e de programação orçamentária 
RAMIOS, R. \& WITT, A. - O curso de planejamento da Faculdade de Saúde Pública da liniversidade de São Paulo: ensaio de avaliacão. Rev. Saúde públ., S Paulo, 8:155-62. 1974.

- incluindo a execução de trabalhos práticos com a manjpulação de modelos docentes. Esta unidade é complementada com a realização do trabalho de campo, durante o qual, em área programática previamente selecionada, os participantes do curso têm oportunidade de aplicar algumas das técnicas estudadas e sentir. em situações reais, as dificuldades habitualmente encontradas. em particular aquelas ligadas à escassez e deficiência da informação estatística;

4) uma quarta unidade, com duração de uma semana. é reservada para apresentação de alguns temas de interesse prático, tais como: técnicas de articulação inter-setorial, uso combinado das técnicas de planejamento, organização e funcionamento de uma unidade setorial de planejamento de saúde. e estratégia para a implantatação do processo de planejamento de saúde;

5) finalmente. a última semana do curso é utilizada para a realização de uma série de seminários de revisão geral, ocasião em que são debatidos temas de interesse em planejamento: a infra-estrutura estatística e o planejamento de saúde; aspectos sociológicos a considerar no processo de planejamento de saúde; as técnicas de planejamento do setor saúde; institucionalização do processo de planejamento de saúde em nível central.

Coincidindo com o encerramento do curso, procede-se a uma avaliação. na qual, utilizando questionários próprios. os participantes têm oportunidade de manifestar sua opinião sobre vários aspectos: duração do curso e horário das atividades diárias. seqüência observada na apresentação das diferentes disciplinas. conteúdo. modo de ministração e possível utilidade prática de cada uma delas, sugestōes quanto à inclusão de outras disciplinas. etc. Parte-se assim. da concep- ção dos cursos de planejamento como um processo circular acumulativo. no sentido de que a avaliação realizada ao final de cada um deles conduz ao aperfeiçoamento do curso seguinte. Com efeito, várias modificações têm sido introduzidas no curso. com base nos depoimentos colhidos nessas avaliaçôes.

Cabe ponderar, todavia. que a ava. liação feita nas condições mencionadas traduz tão somente a opinião dos alunos quanto ao curso em si. nada podendo adiantar sobre a real utilidade e aplicabilidade. nos serviços de origem. dos conhecimentos e técnicas ministrados. Daí a idéia desta pesquisa junto a egressos dos cinco primeiros cursos realizados pela Faculdade. entre 1968 e 1972. visando à obtenção de elementos mais objetivos. inclusive quanto à existência de circunstâncias extra-curso capazes de dificultar ou mesmo impedir a plena aplicação daqueles conhecimentos e técnicas.

\section{PROCEDI M E N TOS}

Para o levantamento das informações foi adotado como instrumento o questionário. considerado no caso o melhor meio. face à homogeneidade da situação social. rapidez na coleta dos dados e preenchimento no momento mais oportuno. fatores que podem concorrer para maior correção das respostas.

Havendo sido o questionário enviado pelo correio para a maioria dos pesquisados, cabe comentar os efeitos desse procedimento. A grande vantagem consistiu na rápida distribuição dos questionários e seu retorno em curto espaço de tempo, o que, somado à dispensa de entrevistador. tornou bastante econômica esta fase da pesquisa, desenvolvida entre junho e setembro de 1973.

To intuito de facilitar o retorno principal problema encontrado quando a coleta de dados é feita por via postal vários cuidados foram tomados: dimen- 
RAMOS. R. \& WITT, A. - O curso de planejamento da Faculdade de Saúde Pública da Universidade de São Paulo: ensaio de avaliação. Rev. Saúde públ., S. Paulo, 8:155-62, 1974.

sões e extensão apropriadas do questionário, redação simples e clara das questóes e local adequado para o registro das respostas, além de carta do coordenador do curso esclarecendo os objetivos do trabalho e solicitando a colaboração do destinatário.

Apesar das cautelas observadas a fim de se obter o maior número possivel de respostas, muitas não foram conseguidas: de 76 questionários enviados, apenas 40 $(52,6 \%)$ foram respondidos em condiçôes de comportarem análise. Algumas causas dessa evasão puderam ser identificadas, tais como: doença grave do destinatário. falta de atualização do endereço, ou ainda mudança do campo de atividades profissionais. E de admitir-se também o extravio de questionários por ocasião da remessa ou da devolução, restando uma parcela não quantificável de casos em que o questionário deixou de ser respondido por esquecimento, desinteresse ou abstenção voluntário do destinatário.

As perguntas constantes do questioná. rio, e de maior interesse para os objetivos da pesquisa, basicamente compreendiam as três áreas seguintes: caracterização do pesquisado (idade, formação unjversitária, cargo ou função), avaliação da situação encontrada no campo (dificuldades para o desempenho das atividades, utilidade dos conhecimentos adquiridos no curso) e consideraçôes gerais (comentários, sugestões, observaçôes complementares).

\section{RESULTADOS}

Em função dos objetivos estabelecidos para esta pesquisa. foram apreciadas as diferentes variáveis existentes, análise essa nem sempre com a profundidade desejável por força das limitações impostas pela natureza dos dados recebidos. Os resultados em sua maioria são apresentados em termos de distribuição de freqüência e respectiva percentagem, excetuando-se as questões abertas que, por não se pres- tarem a uma categorização segura, foram analisadas de forma descritiva.

O total de questionários respondidos que se prestavam para o estudo programado foi. como ficou dito, de cerca de 40, assim distribuídos quanto à formação universitária básica dos pesquisados:

- Medicina ................ 22

- Odontologia $\ldots \ldots \ldots \ldots \ldots \ldots .6$

- Engenharia ............ 4

- Enfermagem ............. 2

- Educação sanitária ......... 1

- Ciências sociais ........... 1

- Outros ................ 2

Cotejando-se estes resultados com os da população total - alunos dos cinco primeiros curso de planejamento - verificou-se que praticamente todas essas categorias profissionais estão representadas de modo proporcional.

Quant o à idade desses profissionais, observa-se que $7(17,5 \%)$ possuem mais de 50 anos, $21 \quad(52,5 \%)$ têm de 36 a 50 anos e os $12(30 \%)$ restantes 35 anos ou menos.

Como foi ressaltado anteriormente, um dos pontos centrais deste estudo prendese à identificação das dificuldades encontradas pelos profissionais no desempenho de suas funções na área em que se especializaram - planejamento de saúde. Tais dificuldades assim se distribuem:

- Deficiências da máquina administrativa $\ldots \ldots \ldots \ldots \ldots \ldots .30$

- Insuficiência de pessoal ...... 26

- Insuficiência de verbas ....... 19

- Falta de apoio local ........ 11

- Falta de apoio central ....... 9

- Falta de apoio regional ....... 6 
RAMOS, R. \& WITT, A. - O curso de planejamentc da Faculdade de Saúde Pública da Universidade de São Paulo: ensaio de avaliação. Rev. Saúde públ., S. Paulo, 8:155-62, 1974.

Como se pode verificar, a dificuldade apontada com maior frequêencia diz res peito à deficiência da máquina adminisIrativa: $75 \%$ dos entrevistados encontraram esse problema. Entretanto, a freqüência da dificuldade que aparece em segundo lugar - insuficiência de pessoal - não é significativamente menor, posto que corresponde a $65 \%$.

Os demais problemas identificados pelos pesquisadores, e que se referem à falta de apoio local, regional e central, alcançam também, tomados conjuntamente, a proporção de $65 \%$, e deles o mais freqüente é o primeiro, encontrado por $27.5 \%$ dos entrevistados.

Cabe salientar ainda, dentre as dificuldades sentidas no campo, as relativas não propriamente à escassez de recursos humarios, mas à insuficiente qualificação desse pessoal que, via de regra, desconhece os mais elementares princípios de planejamento, criando assim obstáculos à implantação e desenvolvimento dos programas; esse despreparo é observado nos diferentes níveis das organizaçōes de saúde.

Outro problema aparentemente existente, conforme se pode depreender das informações recebidas, é a falta de entrosamento entre os elementos das áreas técnica e administrativa, dificuldade seguramente derivada da anterior,

Como já se teve oportunidade de assinalar. o curso objeto desta análise destina-se ao preparo de profissionais para o desempenho de atividades de planejamento do setor saúde, circunstância que torna de especial interesse o conhecimento $d a$ utilização desse recurso humano após a conclusão do curso. As respostas às perguntas formuladas neste sentido evidenciam que praticamente todos os egressos do curso exercem funções direta ou indiretamente relacionadas ao planejamento de saúde, tais como: chefia de unidades centrais ou regionais de planejamento, direção de divisões regionais de saúde, direção de órgãos técnicos centrais, assis. tência técnica a órgãos regionais, etc. Parte dos pesquisados, ou seja, 25\%, não mudaram de cargo após a realização do curso, mas vale ressaltar que vários deles já exerciam anteriormente funções de planejamento, enquanto outros desenvolvem atividades docentes em institutos universitários, contribuindo para a divulgação do processo.

No tocante à utilidade dos conhecimentos ministrados no curso de planejamento, observa-se acentuada divergência de opinião entre os pesquisados, segundo hajam eles acompanhado o curso de saúde pública em época mais recuada ou em anos recentes, particularmente a partir de 1968. Assim é que estes últimos manifestaram a opinião de que, embora algumas disciplinas apresentem utilidade prática, poderiam ser excluídas do curso ou ter reduzida sua carga horária, uma vez que seu conteúdo já era conhecido do curso de saúde pública; nesta situação foram citadas com maior freqüência as disciplinas elementos de administração e elementos de estatística. Entre as matérias sugeridas em substituição, aparecem mais amiúde as relacionadas a técnicas de análise administrativa e matemática, tais como: processos matemáticos de tomada de decisóes, noções de processamento eletrônico de dados, organização e métodos para sistemas administrativos. análise de sistemas de saúde.

As cinco disciplinas constantes do programa do curso, e citadas pelos pesquisados em geral como as de maior utilidade prática no desempenho de suas funções. foram as seguintes:

- Introdução ao planejamento $92,5 \%$

- Elementos de administração $90,0 \%$

- Trabalhos práticos ...... 75,0\%

- Técnica de programação do setor público $\ldots \ldots \ldots \ldots \ldots, 65,0 \%$

- Elementos de economia ... $62,5 \%$ 
RAMOS, R. \& WITT, A. - O curso de planejamento da Faculdade de saúde Pública da Universidade de São Paulo: ensato de avaliação, Rev. Saùde públ., S. Paulo, 8:155-62, 1974.

Um estudo mais detalhado da utilidade prática das disciplinas do curso evidenciou diferenças de opiniāo, de acordo com a formação básica dos entrevistados: assim é que, enquanto os médicos apontaram como mais úteis elementos de administração, introdução ao planejamento e trabalhos práticos (em ordem decrescente), os odontólogos indicaram introdução ao planejamento, técnica de programação local e técnica de programação do setor público. A divergência de opinião entre os duis grupos profissionais com maior representação no curso, talvez se possa atribuir ao fato de que, mais frequientemente que os odontólogos, são os médicos designados para cargos de direção (diretorias regionais e grandes departamentos centrais), no exercício dos quais encontram oportunidade de aplicação dos conhecimentos de administração geral e pública prelecionados no curso; já os odontólogos são de preferência designados para cargos técnicos em órgãos centrais e regionais de planejamento, cujas funções envolvem a manipulação das técnicas metodológicas específicas.

\section{COM E N TAR I O}

Os subsídios colhidos da análise dos questionários recebidos - refletindo o ponto de vista de 40 egressos dos cursos de planejamento da Faculdade - sugerem considerações de duas ordens: umas, ligadas ao curso em si, em termos de organização e conteúdo; e outras, atinentes a realidade institucional vivida pelos participantes após a conclusão do curso.

No primeiro caso, os depoimentos prestados pelos pesquisados indicam que, no consenso da maioria, o curso atende ao seu propósito fundamental, transmitindo aos que o têm acompanhado apreciável volume de conhecimentos de utilidade prática para o desempenho da função planejadora.

Conquanto se reconheça a validade das sugestôes no sentido da redução ou eli- minação de algumas disciplinas do programa introdutório - especialmente elementos de administração e elementos de estatística - não se considera aconselhável a adoção dessa medida a curto prazo.

Ocorre que os participantes, como ficou visto, constituem um grupo de profissionais bastante heterogêneo no tocante à formação básica, com a circunstância adicional de haverem feito seus cursos de saúde pública em épocas e estabelecimentos diferentes, o que fatalmente impõe a necessidade da uniformização de conceitos.

Acresce que, via de regra, os candidatos revelam acentuado desconhecimento dos princípios da moderna ciência da administração, particularmente nos aspectos ligados à organização informal, hoje considerados de importância fundamental na implantação de qualquer processo de mudança.

Cabe finalmente lembrar que numerosos egressos do curso, sobretudo médicos, tèm sido designados para altos cargos de direção nas instituiçōes a que pertencem, no exercício dos quais encontrarão apoio seguro numa razoável soma de conhecimentos de administração.

O mesmo se diga em relação a outras disciplinas do programa introdutório, especialmente estatística, cujos métodos são imprescindíveis tanto para fins de realização do diagnóstico de saúde da comunidade como para a aplicação de certas técnicas de planejamento.

Bem mais graves que as deficiências do curso se afiguram as dificuldades de natureza institucional, apontadas pelos participantes, e atrás enumeradas.

É sabido que, em matéria de planejamento de saúde, o Brasil e de modo geral os países da América Latina atravessam no presente a chamada fase de criação de pré-condições para implantação do processo. Tais pré-condições envolvem a efetivação de medidas em três áreas distintas mas estreitamente relacionadas: reformulação das estruturás e procedimen- 
RAMOS, R. \& WITT, A. - O curso de planejamento da Faculdade de Saúde Pública da Innversidade de São Paulo: ensaio de avaliacão. Rev. Saúde pübl., S Paulo, 8:155-62, 1974.

tos administrativos, capacitação de recursos humanos e montagem de adequados sistemas de informação estatística.

É igualmente sabido que a partir da promulgação do decreto lei n. $200-$ dispondo sobre a reforma administrativa na esfera federal - as unidades da Federação passaram a contar com um instrumento valioso, capaz de impulsionar providência idêntica na esfera estadual. o que de fato rem acontecendo.

Todavia, ao que parece, pelo menos no campo da saúde, a reformulação das estruturas limitou-se aos aspectos puramente formais, não foi acompanhada na esca. la desejável da motivação do pessoal distribuído pelos vários níveis de autoridade e responsabilidade, e nem tampouco se beneficiou da continuidade administrativa indispensável à consolidação do processo.

Desse conjunto de fatores negativos derivam muitas das dificuldades acusadas pelos planejadores preparados na Faculdade. Mas deriva também a necessidade de que as organizações de saúde, ao lado de medidas tendentes à consolidação das reformas iniciadas em suas estruturas, dispensem maior atenção aos programas de capacitação de recursos humanos — outra das pré-condiçôes citadas - não apenas em termos de preparação de sanitaristas e planejadores, mas como preocupação permanente que se estenda ao pessoal de todos os níveis, inclusive da área administrativa. Somente assim se poderá assegurar suporte à atividade planejadora. cujo êxito, em última análise, depende do funcionamento harmonioso de todas as peças da organização.

\section{CONCLUSOES}

A avaliação que vem de ser feita do curso de planejamento do setor saúde, da
Faculdade de Saúde Pública da LSP, sugere as seguintes conclusões:

1. considerado em conjunto, o curso vem atingindo seu objetivo central. ao proporcionar a seus participantes conhecimentos e técnicas que os capacitam para o exercício da função planejadora ;

2. na opinião dos entrevistados, as disciplinas julgadas de maior utilidade prática foram: introdução ao planejamento, elementos de administração, trabalhos práticos, técnica de programação do setor público e elementos de economia;

3. considera-se prematura qualquer modificação substancial na estrutura do curso, tendo em vista a heterogeneidade de formação básica dos candidatos e o fato de haverem feito curso de saúde pública em épocas e estabelecimentos diferentes;

4. via de regra, as organizações de saúde estão aproveitando de maneira adequada os egressos do curso de planejamento, indicando-os para o exercício de funções direta ou indiretamente relacionadas com essa atividade;

5. uma mais ampla utilização dos planejadores rem sendo dificultada pela deficiência da máquina administrativa dos serviços de saúde, pela escassez de recursos humanos e financeiros e pela falta de apoio central. regional e local;

6. como medidas tendentes a equacionar os problemas existentes, sugerese a consolidação das reformas estruturais iniciadas e a execução de programas de treinamento de pessual em todos os níveis administrativos. 
RAMOS, R. \& WITT, A. - O curso de planejamento da Faculdade de Saúde Pública da tniversidade de São Paulo: ensaio de avaliação. Rev. Saúde públ., S. Faulo, 8:155-62, 1974.

RSPU-B/212

Ramos, R. \& WitT, A. - [The course on health planning of Public Health School of University of S. Paulo: evaluation test.] Rev. Saúde públ., S. Paulo, 8:155-62, 1974.

SUMMARY: After describing the organization and contents of the course on health planning, of Public Health School of U.S.P., the Authors relate the results obtained through a research with the professionals prepared in such courses from 1968 to 1972. In spite of some deficiencies pointed out in the course, the opinion of almost all of the interviewers was that the knowledges and techniques given in the course confere them large capacity for carrying out planning activities. The major difficulties found are related to the administration of the health services, to personnel and material shortage and to the lack of central, regional and local support. Some suggestions are made in order to eliminate or reduce such difficulties.

Uniteras: Health planning (course)*; Public Health School of S. Paulo University*; Evaluation*; Health planning training*; Human resources.

REFERENCIA BIBLIOGRÁFICA

1. RAIIOS, R. - O treinamento de planejadores do setor saúde. Rev. Saúde puibl., s. Paulo, z:207-15, 1968.
Recebiao para publicascó em 19/2/19r4

Aprovado para publicacio em $22 / 4 / 1974$ 